\title{
Comparing of Bone's Mineral Content and Density in Youth Artistic Gymnastics
}

\author{
Seyyed Mohsen Hosseini ${ }^{1}$, Ali Yaghobi ${ }^{2}$, Mohammadbagher Forghani Ozrudi ${ }^{3 *}$ \\ ${ }^{1}$ MA Physical Education, Education Office, Iran \\ ${ }^{2}$ Student of Sport Management, Islamic Azad University, Iran \\ ${ }^{3}$ Young Researchers and Elite Club, Azad University, Iran
}

*Corresponding author: Mohammadbagher Forghani Ozrudi, Young Researchers and Elite Club, Qaemshahr Branch, Islamic Azad University, Qaemshahr, Iran

Submission: 海 August 22, 2018; Published: 眥 October 25, 2018

\begin{abstract}
The object of this study is to compare bone mineral content and accumulation in youth gymnast of artistic field to non-athlete. About 15 youth gymnasts has been selected randomly and in the artistic group of has contributed. Also, about 15 have been put in control group of those who did not have any regular gymnastic activity. Bone mineral accumulation and its content have been measured in waist era by Dual Energy X-ray absorptiometry (DXA) measuring. to measure the neutrality of datum distribution among studied groups, we have used of Kolmogorov- Smirnoff test and to test research hypothesis including comparing two study groups, we have used of one-way variance analysis and t-test. Datum has been analyzed by SSPS22 software and in 0.05 meaningful levels. The amount of bone accumulation in waist era among tested two groups does not have meaningful difference ( $p>0.05$ ). The types of artistic gymnast create outstanding effects on bone compound in the youth. Perhaps the cause of increasing accumulation and bone content is mechanical load effect on bones and special characteristic of gymnastic.
\end{abstract}

Keywords: Bone mineral; Bone density; Artistic gymnastic

\section{Introduction}

Regular exercise during childhood and adolescence, a strategy to protect the health of aging adults and is personal. Exercise to build and maintain strong bones are essential in life [1]. The best type of exercise to stimulate bone activity that affects all bones and it is nothing more than weight-bearing exercise [2]. Physical activity is the basic factor in improving children growth till adolescence [3]. In recent years, followed by developing in technology and mechanized daily living, the style of life has been changed. Therefore, peoples are in danger if different diseases like metabolic, heart disease, blood vessels and osteoporosis. In addition to the muscles and organs and bones of the human body to protect and maintain their mobility and daily activities involved in major [4]. Based on international institute of osteoporosis, more than 200 million of the world women are in danger of this disease [5]. The most of bone mass has been achieved in childhood and especially the most accumulation of mineral material in bone and bone analysis are the most important indicators in osteoporosis on adolescence [6]. Bone mineral density in childhood and youth increases gradually to reach its most amount [7]. Where's it doubles in the beginning of maturity to the beginning of [8]

Naturally the peak of bone mass has been maintained from 40 to 45 years old and after then decreases in every year about $0.5 \%$ [9]. In this case, the styles of living and physical activity are very important and if the skeleton doesn't experience body mass, they are in danger of osteopenia and at last osteoporosis [9]. Therefore, recognizing and finding better method in gaining the most optimum mineral accumulation in bone is very important in under years. When people contribute in physical activity, mechanical forces acting on bones, help to maintains bone thickness and their compression. Even gentle movement activity could avoid bone context exhausting and increases bone mineral material in adult. In fact, the most researchers in this era have agreement in which the procedure of increasing mineral material and enriching bone compound is very stable in childhood and youth $[10,11]$. Contributing in exercise and physical activity in growth years increases bone mineral material $[12,13]$, bone mineral content $[14,15]$, bone strength. Generally tensional exercise creates more estrogenic advantages to less tension exercise and enduring lesser weight $[14,15]$. If maturity begins before excursive, it does have more advantages for bones [16-18].

There is a testimony in which the effect of rhythmic gymnastics on skeleton is the same as artistic gymnastic [19]. Some testimonies suggested artistic gymnastic is stronger stimulant to rhythmic gymnastics on skeleton. Those exercising which are along stable changes in acted stress on bones are more effective physical activity for youth in growth [20]. Silva et al. [21] Results showed higher mean values in the proximal femur region of tennis and 
soccer players $(1.02 \pm 0.18 ; 0.96 \pm 0.16$, respectively) than swimmers and controls $(0.91 \pm 0.14$ and $0.87 \pm 0.06$, respectively) $(\mathrm{P}<0.05)$. In relation to the impact of sporting activities based on bone age determination, we observed significant differences in bone mineral density at all evaluated sites at the end of puberty (16-18 years) compared with 10-12 years, with increases of $78 \%$ in the lumbar spine, $47 \%$ in the proximal femur, and $38 \%$ in the whole body [21]

Ferry et al. [22] Results showed body composition and bone mineral density (BMD) were assessed by dual-energy X-ray absorptiometry (DXA). DXA scans were analyzed at the femoral neck by the hip structure analysis (HSA) program to calculate the cross-sectional area (CSA), cortical dimensions (inner end cortical diameter, ED; outer width and thickness, ACT), the centroid (CMP), cross-sectional moment of inertia (CSMI), section modulus (Z), and buckling ratio (BR) at the narrow neck (NN), intertrochanteric (IT), and femoral shaft (FS) sites. Specific BMDs were significantly higher in soccer players compared with swimmers. At all bone sites, every parameter reflecting strength (CSMI, Z, BR) favored soccer players. In contrast, swimmers had hip structural analysis (HSA) Z-scores below the normal values of the controls, thus denoting weaker bone in swimmers. In conclusion, this study suggests an influence of training practice not only on BMD values but also on bone geometry parameters. Sports with high impacts are likely to improve bone strength and bone geometry. Moreover, this study does not support the argument that female swimmers can be considered sedentary subjects regarding bone characteristics [22].

Dowthwaite et al. [17] Results showed, GYM means were significantly greater than NON-means for all variables $(p<0.05)$. At the proximal femur, GYM exhibited narrower periosteal and endosteal dimensions, but greater indices of cortical thickness, BMC, BMD and section modulus, with lower buckling ratio $(\mathrm{p}<0.05)$. However, significant interactions between maturity and loading were detected for the following: 1) FN bone mineral content (BMC) and NN buckling ratio (gymnastics' BMC advantages only in M1 and M3; for BMC and buckling ratio, M1 advantages were greatest); 2) $1 / 3$ radius $\mathrm{BMC}$, width, end steal diameter, cortical cross-sectional area, and section modulus (GYM advantages primarily postmenarche); and 3) UD radius BMC and axial compressive strength (gymnastics' advantages were larger with greater maturity, greatest post-menarche). Maturity-specific comparisons suggested site-specific skeletal adaptation to loading during growth, with greater advantages at the radius versus the proximal femur. At the radius, gymnastics' advantages included greater bone width, cortical cross-sectional area and cortical thickness; in contrast, at the femoral neck, gymnasts bone tissue cross-sectional area and cortical thickness were greater, but bone width was narrower than in NONE. Future longitudinal analyses will evaluate putative maturity-specific differences [17]. This study considered the Comparing of bone's mineral content and density in youth artistic Gymnastics.

\section{Materials and Methods}

This study is of applicable one and in gathering data has been done by field method and the cause after occurring design. in this research, in order to select samples, after required coordination to Mazandaran gymnastics board, at first, we distributed a recall announcement by required explanation about study in GYM, and then after enough explaining to them and their parent and getting letter of satisfaction, personal information questionnaire, physical activity and medical background, about 100 announced readiness. (Two weeks before research beginning) among them, about 15 artistic gymnasts. also, we have done the same about youth nongymnast in control group in which were about 100 and 15 had the same condition like test group. In gathering datum, we suggested to all tested to don't do any unnatural change in their living style one week before research. Contributors did not have any background in bone break, osteoporosis, and disease like diabetes, thyroid more working, heart- breath, and also consuming alcohol, smoking and anti-spasm medicine.

all two tested groups had referred to the center of measuring bone density (Parto-Mazand in Sari city) and in measuring density and bone mineral content, we have used of dual energy x-ray absorptiometry by business name of HOLOGIC and DISCOVERY model w (s/N 84109) made in America and in the year of 2009 and has been used in the L1 vertebral to 14 in waist spinal column. measured parameters normality has been verified in KolmogorovSmirnoff test and then for comparing mean level and mineral density among two groups, we have used of one-way variance analysis and t- test. Datum has been analyzed by SSPS22 software and in 0.05 meaningful levels.

\section{Results}

Table 1 shows the personal characteristic has been tested. (Age, height, weight, body mass indicator).

Table 1: Tested personal characteristic in groups.

\begin{tabular}{|c|c|c|}
\hline & Control Group & Artistic Group \\
\hline Age & $14.7 \pm 0.5$ & $14.8 \pm 0.83$ \\
\hline Weight $(\mathrm{Kg})$ & $53.9 \pm 1.17$ & $53.4 \pm 1.42$ \\
\hline Height (cm) & $165.9 \pm 1.45$ & $165.6 \pm 1.51$ \\
\hline $\begin{array}{c}\text { Body mass indicator } \\
\left(\mathrm{kg} / \mathrm{m}^{2}\right)\end{array}$ & $19.6 \pm 0.62$ & $19.5 \pm 0.71$ \\
\hline
\end{tabular}

Datum normality has been proved in three groups by Kolmogorov-Smirnive test (Table2).

Table 2: K-S test result.

\begin{tabular}{|c|c|c|}
\hline Variable & Control & Artistic \\
\hline Bone mineral content $(\mathrm{g})$ & 0.419 & 0.985 \\
\hline Bone mineral density $\left(\mathrm{g} / \mathrm{cm}^{2}\right)$ & 0.872 & 0.921 \\
\hline
\end{tabular}

In order to examine the difference among groups in density and mineral content in waist, we have used of one-way variance analysis and the result of them has been shown on Table 3. There is meaningful difference among groups in waist skeleton content $(\mathrm{p}=0.003)$. 
Table 3: Comparing waist mineral content among density and skeleton materials in, art and control groups.

\begin{tabular}{|c|c|c|c|c|c|}
\hline Statistics Variables & Mean & SD & df & t & Sig \\
\hline Art group & -1.71 & 1.50 & 14 & -3.68 & 0.003 \\
Control group & & & & & \\
\hline
\end{tabular}

\section{Discussion}

In research literature, the emphasis is on comparing gymnast to other fields or non-active persons [23,24]. The result of this study is in agreement to existing literature [25-27]. There is a testimony gymnast is full of tension exercise influential on bone because of abundant jumping [28]. Full of tension jumping exercise are very influential on developing BMD and BMC [29]. The testimonies show youth gymnasts have had higher BMD to the other field and non-active persons. it should be mentioned in this study, all athletes in the two groups of test and control has been selected by the similar weight and height to does not have any influence on the result because of the importance of height and weight on the amount of density and bone mineral content. This result is not the same Matthews et al. [14], Modlesky et al. [24] findings. Perhaps environmental factors, feeding difference or personal difference in groups are of influential factors in this ground. But the amount of BMD has has meaningful difference among artistic to the control group Perhaps we could say this study has emphasis on exercise influence on adult bone density, but our study is about youth. The above-mentioned matter shows the influence of full of tension exercise on youth bone density $[16,18,30]$.

In any case, it shows perhaps acting mechanical forces resulting from contributing the two artistic and trampoline gymnastics, creates similar adaptability in mineral density and as a result we have skeleton stability in waist era [25]. It has emphasis on gymnast exercise as an influential strategy in increasing mineral density in youth for increasing skeleton power in avoiding osteopenia and osteoporosis [26,27]. These testimonies are along with all studies has been done in this era and explain acting mechanical forces of artistic gymnastic in growth years creates special adaptability in skeleton geometry $[19,26]$. In similar study, boon stingless and cooperative has compared long term influence of power and ability exercise in which jive has different kinematic like differences among artistic and trampoline gymnastic. Findings show superiority of ability exercise to power in increasing BMD and developing skeleton density in waist eras [31-33]. The results suggest gymnasts doing exercise in youth for increasing content and density of mineral materials. according to the importance of increasing density and bone mineral contents to the peak in youth, for preventing osteoporosis in future [26,27], based on study literature suggest gymnastic have has better influence than other fields, we suggest recommending contributing in exercise for nonactive persons

\section{References}

1. 'Gaeini AA, Rajabi H (2015) Physical fitness. The study and compiling books of Social Sciences. Samt publication, Tehran, Iran.
2. Keshmiri R (2012) Osteoprosis: Pathophysiology, Diagnosis \& Treatment. ISMJ 15(2): 157-159.

3. Hosseini SM, Hejazi SM, Yasrebi MA (2013) Comparing of bone's mineral content and density in youth artistic and trampoline gymnastics. International Journal of Sport Studies 3(11): 1252-1258.

4. Bijeh N, Atazade Hoseini SR, Hatef HR (2007) Comparison of bone mineral density (BMD) and muscle strength in girls' sports (volleyball and taekwondo) and non-athletes. Journal of Medical Sciences 9(2): 83-90.

5. Joo I, Sone T (2003) Effects of endurance exercise on three-dinlensional trabecular bone in young grouing rats. Bone 33(4): 485-493

6. Boot AM, de Ridder MA, Pols HA, Krenning EP, de Muinck Keizer-Schrama SM (1997) Bone mineral density in children and adolescents: relation to puberty, calcium intake, and physical activity. J Clin Endocrinol Metab 82(1): 57-62.

7. Davies J, Evans B, Gregory J (2005) Bone mass acquisition in healthy children. Arch Dis Child 90(4): 373-378.

8. Katzman DK, Bachrach LK, Carter DR, Marcus R (1991) Clinical and anthropometric correlates of bone mineral acquisition in healthy adolescent girls J Clin Endocrinol Metab 73(6): 1332-1339.

9. Maddalozzo G, Snow C (2000) High intensity resistance training: effects on bone in older men and women. Calcif Tissue Int 66(6): 399-404.

10. Chevalley T, Bonjour JP, Ferrari S, Hans D, Rizzoli R (2005) Skeletal site selectivity in the effects of calcium supplementation on areal bone mineral density gain: a randomized, double-blind, placebo-controlled trial in prepubertal boys. J Clin Endocrinol Metab 90(6): 3342-3349.

11. Courteix D, Lespessailles E, Peres SL, Obert P, Germain P, et al. (1998) Effect of physical training on bone mineral density in prepubertal girls: a comparative study between impact-loading and non-impact-loading sports. Osteoporos int 8(2): 152-158.

12. Bass S, Pearce G, Bradney M, Hendrich E, Delmas PD, et al. (1998) Exercise before puberty may confer residual benefits in bone density in adulthood: studies in active prepubertal and retired female gymnasts. J Bone Miner Res 13(3): 500-507.

13. Karlsson M, Magnusson H, Karlsson C, Seeman E (2001) The duration of exercise as a regulator of bone mass. Bone 28(1): 128-132.

14. Matthews B, Bennell KL, McKay HA, Khan KM, Baxter-Jones AD, et al. (2006) Dancing for bone health: a 3-year longitudinal study of bone mineral accrual across puberty in female non-elite dancers and controls. Osteoporos Int 17(7): 1043-1054.

15. Zouch M, Jaffré C, Thomas T, Frère D, Courteix D, et al. (2008) Long-term soccer practice increases bone mineral content gain in prepubescent boys. Joint Bone Spine 75(1): 41-49.

16. Bradney M, Pearce G, Naughton G, Sullivan C, Bass S, et al. (1998) Moderate exercise during growth in prepubertal boys: changes in bone mass, size, volumetric density, and bone strength: a controlled prospective study. J Bone Miner Res 13(12): 1814-1821.

17. Dowthwaite JN, Rosenbaum PF, Scerpella TA (2011) Mechanical loading during growth is associated with plane-specific differences in vertebral geometry: A cross-sectional analysis comparing artistic gymnasts vs. non-gymnasts. Bone 49(5): 1046-1054.

18. Dowthwaite JN, Rosenbaum PF, Scerpella TA (2012) Site-specific advantages in skeletal geometry and strength at the proximal femur and forearm in young female gymnasts. Bone 50(5): 1173-1183.

19. Dowthwaite J, Scerpella T (2011) Distal radius geometry and skeletal strength indices after peripubertal artistic gymnastics. Osteoporos Int 22(1): 207-216.

20. Dowthwaite J, Scerpella T (2009) Skeletal geometry and indices of bone strength in artistic gymnasts. J Musculoskelet Neuronal Interact 9(4): 198-214. 
21. Erlandson M, Kontulainen S, Baxter-Jones ADG (2011) Precompetitive and recreational gymnasts have greater bone density, mass, and estimated strength at the distal radius in young childhood. Osteoporos Int 22(1): 75-84.

22. Ferry B, Duclos M, Burt L, Therre P, Le Gall F, et al. (2011) Bone geometry and strength adaptations to physical constraints inherent in different sports: comparison between elite female soccer players and swimmers. J Bone Miner Metab 29(3): 342-351.

23. Hind K, Gannon L, Whatley E, Cooke C, Truscott J (2012) Bone cross-sectional geometry in male runners, gymnasts, swimmers and non-athletic controls: a hip-structural analysis study. Eur J Appl Physiol 112(2): 535541.

24. Modlesky C, Majumdar S, Dudley G (2008) Trabecular bone microarchitecture in female collegiate gymnasts. Osteoporos Int 19(7): 1011-1018.

25. Pollock N, Laing EM, Modlesky CM, O’Connor PJ, Lewis RD (2006) Former college artistic gymnasts maintain higher BMD: a nine-year follow-up. Osteoporos Int 17(11): 1691-1697.

26. Scerpella T, Dowthwaite J, Rosenbaum P (2011) Sustained skeletal benefit from childhood mechanical loading. Osteoporos Int 22(7): 22052210 .

27. Scerpella T, Dowthwaite JN, Gero NM, Kanaley JA, Ploutz-Snyder RJ (2010) Skeletal benefits of pre-menarcheal gymnastics are retained after activity cessation. Pediatr Exerc Sci 22(1): 21-33.
28. Silva CC, Goldberg TB, Teixeira AS, Dalmas JC (2011) The impact of different types of physical activity on total and regional bone mineral density in young Brazilian athletes. J Sports Sci 29(3): 227-234.

29. Tournis S, Michopoulou E, Fatouros IG, Paspati I, Michalopoulou M, et al. (2010) Effect of rhythmic gymnastics on volumetric bone mineral density and bone geometry in premenarcheal female athletes and controls ] Clin Endocrinol Metab 95(6): 2755-2762.

30. Vicente-Rodriguez G, Jimenez-Ramirez J, Ara I, Serrano-Sanchez JA, Dorado $C$, et al. (2003) Enhanced bone mass and physical fitness in prepubescent footballers. Bone 33(5): 853-859.

31. Von Stengel S, Kemmler W, Lauber D, Kalender WA, Engelke K (2007) Differential effects of strength versus power training on bone mineral density in postmenopausal women: a 2-year longitudinal study. Br J Sports Med 41(10): 649-655.

32. Vicente-Rodriguez G, Dorado C, Ara I, Perez-Gomez J, Olmedillas H, et al. (2006) Artistic versus rhythmic gymnastics: effects on bone and muscle mass in young girls. Int J Sports Med 28(05): 386-393.

33. Ward K, Roberts SA, Adams JE, Mughal MZ (2005) Bone geometry and density in the skeleton of pre-pubertal gymnasts and school children. Bone 36(6): 1012-1018.
Creative Commons Attribution 4.0

International License

For possible submissions Click Here
Submit Article

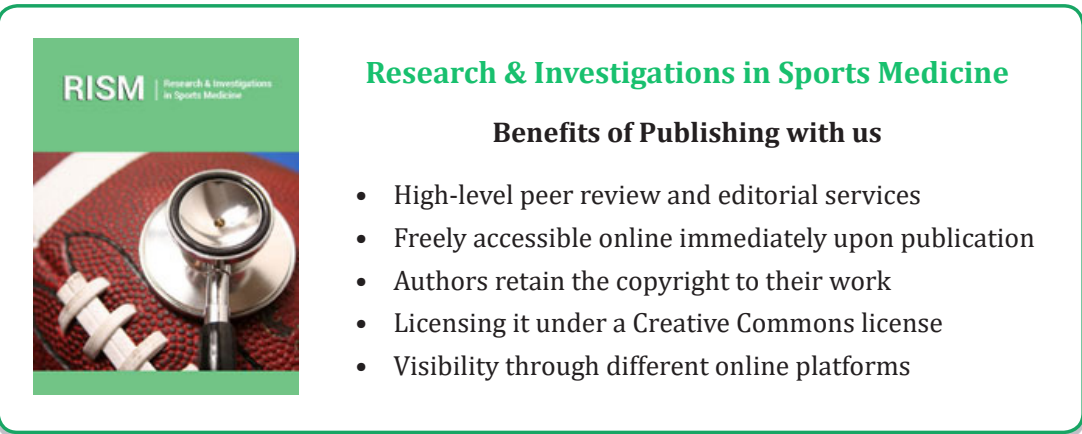

